\title{
SABERES E (IN)VISIBILIDADES DOS CORPOS TRANS NOS ESPAÇOS EDUCATIVOS
}

\author{
Joanalira Corpes Magalhães ${ }^{1}$ \\ Paula Regina Costa Ribeiro ${ }^{2}$
}

\begin{abstract}
RESUMO
Nesse texto, questionamos os significados e as práticas que vão sendo (re)produzidos acerca dos corpos trans, nos diferentes espaços educativos como a ciência, a mídia e os livros didáticos de Biologia. Para tanto, discutimos os corpos como construções discursivas problematizando e desconstruindo a produção dos corpos-homem e dos corpos-mulher pautada numa visão essencialista e binária. Nas análises, percebemos uma explosão de saberes sobre as questões trans na ciência e nas mídias, porém ao olharmos para o livro didático, observamos um silenciamento e uma invisibilidade da temática trans. Assim, discutir a centralidade da categoria corpo nas experiências, nos trânsitos e nas itinerâncias dos sujeitos trans nos espaços educativos, possibilita-nos perceber o quanto a desconstrução dos binarismos torna-se necessária para que possamos reconhecer a multiplicidade de performances de gênero.
\end{abstract}

PALAVRAS-CHAVE: Corpos. Transexualidade. Ciência. Binarismo. Artefatos Culturais.

Knowledge and (In)Visibility of Trans Bodies in Educational Spaces

\begin{abstract}
In this text, we question the meanings and practices that have been (re)produced around trans bodies, in different educational spaces such as
\end{abstract}

\footnotetext{
${ }^{1}$ Pós-doutora em Educação pela Universidade Federal do Rio Grande do Sul - UFRGS. Universidade Federal do Rio Grande - FURG, Rio Grande, Rio Grande do Sul, Brasil. E-mail: joanaliramagalhaes@ gmail.com

${ }^{2}$ Pós-doutora em Educação pela Escola Superior de Educação de Coimbra - Instituto Politécnico de Coimbra. Universidade Federal do Rio Grande - FURG, Rio Grande, Rio Grande do Sul, Brasil. E-mail: pribeiro.furg@gmail.com
} 
science, media and Biology textbooks. For that we discuss the bodies as discursive constructions problematizing and deconstructing the production of the man-body and the woman-body based on an essentialist and binary view. In analyzes, we perceived and explosion of knowledge about trans questions in science and media, but as we look to the textbook, we see a silencing and an invisibility of trans thematic. So, discussing the centrality of the body category in experiences, on transits and roaming of trans people in educational spaces, allow us realize how much the deconstructing of binarisms becomes necessary so that we can recognize the multiplicity of genders performances.

KEYWORDS: Bodies. Transsexuality. Science. Binarisms. Cultural Artifacts.

Pois se o corpo não cessa de ser descoberto, é preciso não perder de vista a provisoriedade de cada conhecimento produzido a seu respeito: constantemente redescoberto, nunca, porém, completamente revelado!

Denise Bernuzzi de Sant'Anna

\section{Introdução}

Ao longo do tempo, observar, dissecar e diagnosticar os corpos dos sujeitos é uma prática que despertou e ainda desperta o interesse da sociedade. Produzir verdades sobre os sujeitos, a partir dos saberes construídos sobre seus corpos, emerge no cenário dos diferentes campos de saberes como formas legítimas de produção do conhecimento. Nesse sentido, os corpos são produzidos, reproduzidos, descobertos e redescobertos como os corpos dos/as transexuais, foco de discussão deste artigo.

Um dos campos de saber acionado para olhar para os corpos tem sido o da Biologia, que vem ensinando sobre a anatomia e fisiologia de homens e mulheres, numa lógica binária, pautada na genitalidade. Esses saberes, produzidos nessa racionalidade científica, constituem o currículo escolar, os livros didáticos, bem como, outros materiais didático-pedagógicos, como os modelos anatômicos, silenciando e invisibilizando outros corpos que rompem 
com a linearidade sexo, gênero e sexualidade, como os sujeitos transexuais. A transexual, Sofia Favero Ricardo, reitera essa discussão destacando que: "Todas as instituições - inclusive o estado - te ensinam a se odiar a partir do momento que coloca em um livro de biologia que você não existe! 'Só existe homem com pênis e mulher com vagina, você é um erro da matrix'." (LUCON, 2014).

A partir da provocação de Sofia Favero Ricardo, passamos a nos questionar sobre os sentidos e significados que vão sendo (re)produzidos acerca dos corpos trans, no campo da ciência, na mídia e nos livros didáticos de Biologia. A fim de discutir a centralidade da categoria corpo nas experiências, nos trânsitos e nas itinerâncias dos sujeitos trans, buscamos problematizar o quanto a desconstrução dos binarismos torna-se necessária para que possamos reconhecer a multiplicidade de performances de gênero. Ou seja, problematizar esse corpo tanto como algo que "temos", como também algo que "somos" e ainda que desejamos modificar para nos adequar aos ideais de ser que construímos. Com isso, não buscamos indicadores universais para as experiências relacionadas aos corpos e aos gêneros, mas, sim, romper com a lógica social, desfazer as amarras e a forma dicotômica de definir corposhomem e corpos-mulher, principalmente quando pensamos no debate dessas temáticas, nos diferentes espaços educativos.

Entendemos por espaços educativos todos aqueles locais que ensinam, que possuem uma pedagogia, ou seja, espaços sociais implicados na produção e no intercâmbio de significados. Assim, a educação ocorre em diversos espaços sociais, tais como: universidade, escola, mídia, instituições religiosas, jurídicas, de saúde e de trabalho, entre outras.

Nesse texto, buscaremos enfocar como alguns desses espaços - ciência, mídia, escola - vêm produzindo significados, através da linguagem e de práticas sobre os corpos trans, a partir dos Estudos Culturais e de Gênero numa perspectiva pós-estruturalista.

Para tanto, num primeiro momento do texto buscamos discutir os corpos como construções discursivas problematizando e desconstruindo a produção 
dos corpos-homem e dos corpos-mulher, pautada numa visão essencialista e binária. Após, discorremos sobre os entendimentos acerca dos corpos trans que têm circulado em alguns espaços educativos como a ciência, a mídia e a escola através dos livros didáticos de Biologia. Finalizamos tecendo algumas considerações a fim de visibilizarmos as experiências trans, seus modos de produção e seus trânsitos em alguns espaços educativos.

\section{Corpos-homem, corpos-mulher: a normalização através da biologia dos sexos}

Esses corpos-homem e corpos-mulher podem ser pensados como um dado biológico ou como uma construção discursiva? Estamos entendendo o corpo, não apenas na sua materialidade biológica, mas articulado aos discursos que o interpelam e o produzem: o corpo como um híbrido, entre o biológico e o cultural? Para Michel Foucault, o corpo é

superfície de inscrição dos acontecimentos (enquanto que a linguagem os marca, as ideias os dissolvem), lugar de dissociação do $\mathrm{Eu}$ (que supõe a quimera de uma unidade substancial), volume em perpétua pulverização. (2007b, p. 22).

O corpo, superfície de inscrição dos acontecimentos, como aponta Foucault (2007b), foi historicamente marcado, dissecado, esquadrinhado, visualizado e (re)descoberto, a cada instante, a partir de novas técnicas de examiná-lo e explorá-lo que foram produzidas em nossa sociedade.

Souza (2007) possibilita-nos pensar em uma materialidade humana que esteja imersa e constituída nas interações com as práticas discursivas que se encontram no meio social e histórico o qual as precedeu, nomeou e nomeia. Para a autora,

este ser - nomeado humano - desde que nasce é imerso em sistemas 
de significação produzidos nas práticas discursivas que, ao instituírem as marcas sociais [...] que o nomeiam, definem e posicionam, dão-lhe um corpo-identidade ou, dito de um outro modo, o tornam sujeito. (Ibid., p. 99).

Por esse viés, não estamos negando a materialidade biológica dos corpos, ou seja, que o pênis e a vagina não sejam marcas biológicas, mas procuramos pensá-las imbricadas às práticas culturais e discursivas que nos ensinam os sentidos que passamos a atribuir aos corpos e as inscrições de gêneros neles expressas. Conforme Louro,

[...] antes de pretender, simplesmente, "ler" os gêneros e as sexualidades com base nos "dados" dos corpos, parece prudente pensar tais dimensões como sendo discursivamente inscritas nos corpos e se expressando através deles; pensar as formas de gêneros e de sexualidade fazendo-se e transformando-se histórica e culturalmente. Não se pretende, com isso, negar a materialidade dos corpos, mas o que se enfatiza são os processos e as práticas discursivas que fazem com que os aspectos dos corpos se convertam em definidores de gênero e de sexualidade e, como consequência, acabem por se converter em definidores dos sujeitos. (2004, p. 80).

Nesse sentido, o corpo por si só, enquanto materialidade biológica pura e simples não expressa o que os sujeitos são, já que produzimos nossos corpos a partir de incrições culturais, sociais, históricas entre outras marcas. Então, alguns corpos borram as fronteiras naturalizadas entre o que é ser homem e mulher, dentre eles os corpos trans, que provocam fissuras no modelo naturalizado de sexo, gênero e sexualidade que oferecem apenas duas possibilidades de existência: pênis-homem-heterossexual ou vagina- mulherheterossexual.

Ao longo do tempo, produziram-se diversas pesquisas, fundamentando na biologia dos corpos a construção de conhecimentos acerca das condutas e comportamentos de homens e mulheres, as quais contribuíram para produzir 
essa correspondência entre a materialidade do corpo - pênis ou vagina - e a forma como o sujeito deveria se reconhecer - homem ou mulher. Os séculos XVIII e XIX foram marcados pela disseminação de discursos científicos que visavam a comprovar que os comportamentos das diversas ordens, mas, principalmente, os sexuais, tinham uma origem na biologia dos corpos (FOUCAULT, 2007a; BENTO, 2006).

Conforme destaca Bento, a linguagem científica

torna-se uma das mais refinadas tecnologias de produção de corpossexuados, à medida que realiza o ato de nomear, de batizar, de dar vida, como se estivesse realizando uma tarefa descritiva, neutra, naturalizando-se. (2006, p. 116).

Assim, ao pensarmos sobre como esses saberes vão construindo os corpos, estamos problematizando a forma como, pela linguagem, nomeamos e damos sentido a essa materialidade biológica. Nesse processo de nomeação e definição dos corpos através da linguagem, ao longo do tempo, foram sendo produzidos corpos binários sexuados e generificados (corpo-homem; corpomulher) tendo como base a genitália.

Através da linguagem, demarca-se e "naturaliza-se" as diferenças entre os corpos. Louro destaca que

dentre os múltiplos espaços e as muitas instâncias onde se pode observar a instituição das distinções e das desigualdades, a linguagem é, seguramente, o campo mais eficaz e persistente tanto porque ela atravessa e constitui a maioria de nossas práticas, como porque ela nos parece, quase sempre, muito 'natural' [...] a linguagem não apenas expressa relações, poderes, lugares, ela os institui; ela não apenas veicula, mas produz e pretende fixar diferenças (2001, p. 65).

Assim, na e através da linguagem os corpos e o gênero vão sendo 
constituídos e marcados, cada sujeito vai sendo posicionado no interior dos diversos grupos sociais.

Para Bento (2010, p. 03), a genitália torna-se um "qualificador para o corpo adentrar à categoria de humano". Assim, através das tecnologias médicas para produção de imagens sobre os corpos, quando se olha no interior do útero e se diz "é um menino" ou "é uma menina” não se está apenas expondo uma situação daquele bebê, mas, sim, neste ato, se inicia um processo de produção de masculinidades e feminilidades baseados na genitália.

Esse bebê existe, como sujeito de sexo e gênero. A partir disso, se constrói uma série de expectativas, de construções sobre cores, nomes, brincadeiras, profissões... Assim, o gênero é pré-discursivo, pois está dado antes mesmo do nascimento e, dessa forma, a nomeação do sexo e do gênero é um ato performativo. Para Arán e Peixoto (2007, p. 134), "se os atributos de gênero são performativos e não uma identidade pré-existente, a postulação de um 'verdadeiro sexo' (FOUCAULT, 1994) ou de uma 'verdade sobre o gênero' revela antes uma ficção reguladora”.

Butler, questiona essa base biológica (sexo) como sendo também construída e desestabiliza-nos ao problematizar o conceito de gênero.

O gênero é o mecanismo pelo quais qual as noções de masculino e feminino são produzidas e naturalizadas, mas ele poderia ser muito bem o dispositivo pelo qual estes termos são descontruídos e desnaturalizados. (BUTLER, 2006, p. 59, apud ARÁN, PEIXOTO, 2007, p. 135).

A autora desconstrói a dicotomia entre sexo/gênero em que o primeiro é considerado como natural e o segundo como cultural para designar ambos, construídos sócio-historicamente. Ao criticar a separação entre sexo e gênero, a autora aponta que o processo de diferenciação sexual não se resume ao aspecto material-físico, mas é um conceito marcado pela construção de práticas discursivas. 
Para Butler, problematizar essa distinção possibilita compreender que o gênero se torna

um artifício flutuante, com a consequência de que homem e masculino podem, com igual facilidade, significar tanto um corpo feminino como um masculino, e mulher e feminino, tanto um corpo masculino como um feminino. (2013, p. 24-25).

Pensar os corpos trans, é pensar o gênero como "um artifício flutuante", uma possibilidade de romper com a lógica binária. Assim, nossa proposta é questionar a produção de saberes sobre os corpos desses sujeitos, problematizando como esses corpos foram e são progressivamente "desvelados" com o objetivo de produzir "verdades" sobre seus corpos e seus modos de ser e estar na sociedade. Bento destaca que:

O corpo-sexuado (o corpo-homem e o corpo-mulher), que dá inteligibilidade aos gêneros, encontra nas existências trans seus próprios limites discursivos, uma vez que aqui o gênero significaraá o corpo, revertendo assim um dos pilares de sustentação das normas de gênero. Ao realizar tal inversão, depara-se com outra "revelação": a de que o corpo tem sido desde sempre gênero e que, portanto, não existe uma essência interior e anterior aos gêneros. Quando se problematiza a relação dicotômica e determinista entre corpo e gênero, outros níveis constitutivos da identidade também se liberam para comporem arranjos múltiplos fora do referente binário dos corpos. (2014, p. 52).

Nesse processo de produção de identidades e composição de arranjos múltiplos, percebemos o quanto as práticas científicas transformaram esses corpos trans em objeto de conhecimento e acabam por produzir saberes, ou seja, categorias, modos de classificação, conceitos e teorias.

Entender os corpos trans como construção, possibilita-nos perceber o 
quanto discursos, pedagogias, práticas sociais, saberes científicos, entre outros, produzem esses corpos e inscrevem determinadas marcas. Os significados produzidos sobre esses corpos deslizam e escapam não apenas porque são alterados, mas porque são objeto de disputas por diferentes saberes e instâncias culturais que falam deles, que afirmam o que eles são, explicam-nos, dizem como são e como devem ser.

Frente a essas questões, destaca-se a importância do debate dessas temáticas e a visibilidade desses sujeitos a fim de desconstruirmos como esses corpos são nomeados de forma binária e discriminados conforme se ajustem, ou não, às normas estabelecidas pela sociedade.

\section{Corpos trans: produção de saberes científicos}

Para pensarmos acerca das (in)visibilidades dos corpos trans, buscamos entender de que forma foi se constituindo esse processo de produção de saberes sobre esses sujeitos trans. Nesse processo, além da criação de um método adequado, alguns espaços foram sendo reconhecidos como próprios e autorizados, como, por exemplo, as universidades, as sociedades científicas, o ensino canônico, as escolas, os laboratórios, o jogo das especializações, o jogo das qualificações profissionais, tudo isso sendo uma maneira de organizar, a propósito de uma verdade, posta pelas ciências como universal, a raridade dos que podem ter acesso a ela. (FOUCAULT, 2006).

Ao pensar na história de produção de saberes sobre os corpos, VeigaNeto (2007) destaca que, para Michel Foucault, as forças, as quais ele nomeou de poder, atuam sobre aquilo que os sujeitos têm de mais concreto e material, ou seja, seus corpos.

Se foi possível constituir um saber sobre o corpo, foi através de um conjunto de disciplinas militares e escolares. É a partir de um poder sobre o corpo que foi possível um saber fisiológico, orgânico. (FOUCAULT, 2007b, p. 148-149). 
Nessa história de produção de saberes, os corpos dos sujeitos foram progressivamente sendo "desvelados". Primeiramente, foi a observação da pele, depois as demais camadas, chegando às vísceras, aos músculos e aos ossos. Com as experiências na área da anatomia, os séculos XIX e XX "são dominados pela teoria celular na biologia e pela patologia celular na medicina. [...] a ciência decifra o código genético, e o século XXI entra [...] nas biotecnologias." (NOVAES, 2003, p. 08). A tradição anatomofisiológica veio a produzir um corpo-objeto, fragmentado, descontextualizado, sem subjetividade, sendo reconstruído a partir do modelo produzido pela medicina, pelas ciências, pela educação escolarizada, pela mídia, ou seja, um corpo objetivado, sem a dimensão subjetiva, "o corpo como algo que temos e não algo que somos." (ORTEGA, 2008, p. 148).

Nesse sentido, e tendo como foco os corpos dos/as transexuais, nos questionamos: Que saberes vêm sendo construídos sobre os corpos dos/as sujeitos/as transexuais? Que práticas científicas, por exemplo, transformaram o corpo humano como objeto de conhecimento e acabam por produzir saberes, ou seja, as categorias, modos de classificação, conceitos e teorias, sobre os sujeitos transexuais? Como, nos processos de educação científica e escolar, os saberes produzidos sobre os/as transexuais vão sendo divulgados e acessados?

Não temos como premissa responder a esses questionamentos, mas pensar o quanto uma série de técnicas e procedimentos foi utilizada para a produção de saberes e verdades sobre os sujeitos. Ao longo do tempo, diversas pesquisas foram sendo produzidas, fundamentando na biologia dos corpos a construção de conhecimentos acerca das condutas e comportamentos de homens e mulheres. Como nosso foco, neste estudo, são os/as sujeitos/as transexuais, buscamos conhecer como se deu a produção sobre esses/as sujeitos/as.

Para Bento (2006), no século XX, o dispositivo da sexualidade teve alguns desdobramentos, sendo um desses, a "experiência transexual". 
A partir de 1950, observa-se um saber sendo organizado em torno dessa experiência. A tarefa era construir um dispositivo específico que apontasse os sintomas e formulasse um diagnóstico para os/as transexuais. Como descobrir o "verdadeiro transexual"? Como diferenciá-lo da travesti e/ou do homossexual? (2006, p. 132).

Esse último questionamento nos provoca a olhar para a história a fim de pensar, mesmo que brevemente, as condições que possibilitaram a invenção do sujeito transexual. Até 1949, não existia uma distinção entre travestis, transexuais e homossexuais, mas, somente na década de 50, que ocorreram as primeiras publicações que defendiam a especificidade do que chamaram de "fenômeno transexual". (BENTO, 2006). Ao longo das décadas de 60 e 70, discursos reguladores dos corpos possibilitaram o surgimento de instituições internacionais que visavam a produzir saberes específicos sobre os/as transexuais e, assim, diferenciá-los/as dos homossexuais masculinos e femininos, bem como de travestis.

Para Bento (2006), na temática da transexualidade encontram-se duas grandes vertentes de produção de saberes: uma relacionada ao funcionamento endócrino do corpo e outra referente às teorias do papel da educação na constituição das identidades de gênero. Contudo, embora dando destaque à visão construtivista, John Money - um de seus defensores - apontava que a transexualidade poderia ser uma anomalia no cérebro, a qual alteraria a imagem sexual do corpo de maneira a torná-la não condizente ao sexo de nascimento.

Em 1973, a transexualidade passou a ser denominada conforme termo criado por John Money, como uma "disforia de gênero". (BENTO, 2011, p. 91). O endocrinologista Harry Benjamin, em 1966, em seu livro, "El fenômeno transexual", estabeleceu os parâmetros que deveriam ser utilizados em clínicas e hospitais para avaliar se os sujeitos que solicitavam a cirurgia de mudança de sexo eram "transexuais de verdade". (BENTO, 2006). Tal 
diagnóstico era realizado através de avaliações que incluiam "histórico completo do caso, testes psicológicos e sessões de terapia”. (Id., p. 47). Em 1969, a Harry Benjamin International Gender Dysphoria Associantion (HBIGDA) tornou-se mundialmente responsável por normatizar o "tratamento" desses sujeitos com a publicação das "Normas de Tratamento (Standards of Care - SOC)" as quais, atualmente, estão em sua sexta edição. (BENTO, 2011).

Além desse documento (SOC), hoje são oficialmente reconhecidos no diagnóstico de transexuais outros dois documentos: o Manual de Diagnóstico e Estatístico de Transtornos Mentais (DSM) - da Associação Psiquiátrica Norte-Americana (APA), hoje, em sua quinta versão (2014) que define a transexualidade como uma doença, sendo nomeada como "disforia de gênero" - e o Código Internacional de Doenças - da organização Mundial de Saúde -, atualmente, na sua décima versão (2008) que classifica a transexualidade como um "transtorno da identidade sexual".

Dessa forma, entendemos que, ao definir características e classificar a transexualidade como patologia, os saberes científicos naturalizam tal experiência, reforçando as normas que definem os gêneros de maneira distinta e de acordo com o sexo biológico, bem como universaliza o que é ser transexual determinando padrões de verdade sobre esses sujeitos.

\section{Corpos trans: saberes que circulam na mídia}

Pensar sobre essa explosão de saberes de ordem científica acerca das questões trans nos desafia a ampliar nossos olhares e problematizações a fim de pensarmos os processos de educação científica e os outros espaços que também nos educam para além do escolar. Nesse processo, há uma espécie de transposição daqueles saberes produzidos e noticiados em determinados meios de divulgação da Ciência - periódicos e revistas científicas especializadas - os quais são destinados e acessados por um público específico (pesquisadores/as, comunidade científica, universidades, etc.) para outras 
redes tecnológicas de comunicação (mídia impressa, ondas de rádios e televisão, computadores, etc.) acessadas e destinadas a um público geral.

Nesses processos, ocorre o cambiante movimento de significados e saberes de um texto científico para o texto midiático, da linguagem científica para outro tipo de linguagem. Assim, precisamos entender a mídia como mediadora e (re)produtora desses discursos, como um dos espaços sociais que nos educam, possibilitando-nos problematizar o quanto torna-se relevante percebermos a potencialidade dessa propagação de ideias, significados, conhecimentos e valores, no sentido de discuti-las nos tempos e espaços escolares, promovendo aprendizagens do mundo e sobre o mundo (MELO; TOSTA, 2008). Dessa forma, pensar nas potencialidades para debatermos e incluirmos as temáticas de corpos, gêneros e sexualidades no currículo de Biologia, nos instiga a estar atentos/as aos processos de mediação de discursos produzidos pela Ciência.

$\mathrm{Na}$ contemporaneidade percebemos o quanto essa explosão de saberes sobre as questões trans passa a ser veiculada em diferentes mídias (impressa, digital, televisiva, entre outras). A mídia, entendida como um espaço educativo, ao veicular os saberes produzidos pela ciência, promove, de certa forma, a divulgação científica.

Como exemplo, podemos citar o site G1, em que na sessão Ciência e Saúde, encontramos a reportagem de 03 de março de 2013, intitulada “Transexual pode se descobrir já na primeira infância, dizem especialistas”, a qual destaca que as crianças devem ter avaliação psicológica e que os pais precisam dialogar com a escola. Além disso, apresentam o caso de um garoto de 6 anos que se vê como menina. Abaixo destacamos um dos trechos da reportagem: Transexual é a pessoa que tem um transtorno mental e de comportamento sobre sua identidade de gênero, ou seja, nasce biologicamente com determinado sexo, mas se vê pertencente a outro e cogita fazer tratamentos hormonais e cirurgia para mudar o corpo físico. (D'ALAMA, 2013).

Através desse trecho podemos perceber o quanto o discurso científico é colocado em funcionamento na reportagem, a fim de explicar o que seria uma 
pessoa transexual. Além disso, mencionar o desejo de enquadrar-se na norma binária de corpo, através de hormônios e cirurgias, é colocado como o "natural" de todas e todos transexuais.

Outro exemplo é a edição do dia 23 de setembro de 2016, do programa de televisão Globo Repórter. No site do programa encontramos a seguinte matéria "Transgênero: origem pode ser biológica e começar na gestação". Neste trecho do programa, a ênfase está em destacar uma das hipóteses científicas que seria que nas pessoas transgêneras, a identidade que se forma no cérebro (feminina ou masculina) não estaria em sintonia com o órgão sexual devido a um desenvolvimento não coerente no feto entre genitália e cérebro (GLOBO, 2016). Percebemos nessa reportagem, novamente a materialidade biológica dos corpos sendo colocada em destaque para justificar a questão da transexualidade.

No ínicio do ano de 2016, o Comitê Olímpico Internacional (COI) realizou uma mudança na sua resolução com relação aos e às atletas trans. De acordo com o COI, homens poderiam participar dos eventos da entidade sem ter nenhuma restrição e as mulheres, para competir em equipes femininas, deveriam ter a quantidade de testosterona controlada no sangue nos 12 meses anteriores à competição. Nessa resolução, não há necessidade de cirurgia de redesignação genital. Tal resolução causou e ainda causa uma série de comentários relacionados a algumas vantagens que esses e essas atletas, principalmente mulheres trans, teriam em relação aos e às atletas cis, sendo as justificiativas pautadas sempre pelo viés biológico e hormonal ao pensar as performances esportivas desses corpos.

Em contraponto a isso, o site NLUCON (http://www.nlucon.com/2017/03/atletas-trans-levam-vantagens-em.htmlO) publica em 26 de março de 2017 uma matéria intitulada "Atletas trans levam vantagens em competição? Saiba por que isso é desculpa para ser transfóbico" em que busca trazer argumentações que descontroem a ideia da vantagem biológica dos e das atletas trans, problematizando o quanto a biologia é enfatizada para justificar e determinar os sujeitos e suas posições sociais. 
Outra reportagem que possibilitou uma grande repercussão para a questão da transexualidade, nos últimos anos, foi a edição de fevereiro de 2015 da Revista Nova Escola. A capa da revista apresentava a imagem do menino britânico Romeo Clarke, de 5 anos, com roupa de princesa e sua matéria tinha como foco os/as educadores/as, público alvo da revista, e o debate sobre as questões de gênero e sexualidade na escola, sobretudo com relação às situações em que crianças e jovens rompem com as regras socialmente aceitas sobre ser homem ou mulher. Tal reportagem da Revista Nova Escola obteve uma ampla discussão sobre a temática, sendo que a repercussão advinda apresentou milhares de acessos e comentários no website da revista. Mesmo com inúmeras críticas de leitores/as que discordaram da abordagem da revista, a publicação constitui um movimento que, de certa forma, vai adentrando em diferentes espaços e garantindo uma visibilidade das discussões que envolve gênero e sexualidade no espaço escolar, o que dá visibilidade ao tema da transexualidade.

Ainda, suscitando esses acontecimentos que possibilitaram a visibilidade e discussão acerca da questão da transexualidade, na mídia televisiva, temos como exemplos alguns programas da televisão aberta e fechada. Um exemplo é o programa, "Liberdade de Gênero", do canal por assinatura GNT, exibido em uma série na qual diferentes pessoas narram histórias de vida e de não identificação delas com o gênero que designou-as ao nascerem, o que contribui-nos a pensar em gênero para além da análise dos atributos masculinos e femininos determinados nas sociedades.

Também foi exibida a série, "Quem sou eu?," produzida pelo programa Fantástico, da Rede Globo, que abordou - a partir da metáfora da história de "Alice no País das Maravilhas", e da fala de médicos/as e de pessoas trans aspectos da vida de indivíduos transgêneros em diferentes momentos da vida, como a infância, a adolescência e a fase adulta, período este em que ocorrem os tratamentos hormonais, as cirurgias e a vida pós-transição.

Outros programas da mesma emissora que abordaram a temática trans foram: "Profissão Repórter" que trouxe, no mês de junho de 2016, jovens trans 
para falarem sobre o preconceito e a violência que vivem diariamente; o programa "Encontro com Fátima Bernardes", em fevereiro de 2017, no qual a apresentadora conversa com um psiquiatra sobre crianças transgêneras e com a mãe de uma menina de 10 anos, que nasceu menino, mas nunca se identificou com o gênero de nascimento; e, ainda, no ano de 2017, a novela intitulada, "A Força do Querer", que tinha uma personagem que transicionava de mulher para homem.

Essas mídias são alguns exemplos das diferentes formas que, em nossa sociedade, os saberes da ciência são postos em funcionamento, acessam e são acessados pelos sujeitos e regulam suas condutas. Essas mídias, ao incorporarem em seus discursos algumas enunciações científicas, colocam em funcionamento a engrenagem saber, poder e corpo. Esses artefatos constroem formas de ver e perceber os corpos, os sujeitos e suas marcas biológicas. Neste sentido, estamos entendendo que as diferentes mídias não apenas apresentam a temática da transexualidade, mas, ao falar sobre, atuam também como "produtora de saberes e formas especializadas de comunicar e produzir sujeitos, assumindo, nesse sentido, uma função nitidamente pedagógica.” (FISCHER, 1997, p. 61).

Essas pedagogias culturais não podem ser tomadas como neutras, pois produzem e ensinam saberes, condutas e identidades. Ao falar sobre os corpos de homens e mulheres, neste caso, pessoas trans, as mídias acabam instituindo maneiras de perceber, classificar, identificar, esquadrinhar, detalhar e entender esses sujeitos.

Contudo, ao passo que percebemos essa explosão de saberes sobre as questões trans em diferentes espaços educativos, como a ciência e as mídias anteriormente citadas, e, ao olharmos para o espaço da escola e os artefatos que ali circulam, como o livro didático, podemos observar um silenciamento. ao centrarmos nosso foco para o ensino de Biologia, já que o que se faz presente é a invisibilidade da temática trans, conforme discussão realizada no próximo tópico que compõe esse artigo. 


\section{Corpos trans: silenciamento nos livros didáticos de biologia}

Os livros didáticos fazem parte da cultura escolar, das políticas públicas de educação e são um campo discursivo potente no sentido de instituir verdades e produzir subjetividades.

Destacamos que o livro didático não é o único subsídio para a prática pedagógica, mas ele faz parte de uma política governamental - Programa Nacional do Livro Didático - em que alunos/as de escolas públicas recebem gratuitamente esse material. Assim, o livro didático não é o único material que o/a professor/a utiliza, mas ele é um artefato acionado intensamente durante os processos de ensinar e aprender presentes nos espaços formais de educação. Sendo assim, os discursos apresentados nos livros didáticos vão imprimindo algumas marcas nos modos de ser, pensar e agir dos/as estudantes.

Sendo o livro didático um artefato cultural bastante utilizado pelos/as professores/as nas salas de aula, necessita corresponder às atuais exigências de uma educação para o século XXI, às quais o conhecimento, os valores, as capacidades de resolver problemas, aprender a aprender, assim como a alfabetização científica e tecnológica, são elementos essenciais. Assim, o livro didático não pode continuar apenas como fonte de conhecimentos a serem transmitidos pelo/a professor/a e com objetivo de serem memorizados e repetidos pelos/as alunos/as.

O livro didático de Biologia, sendo um artefato cultural, deve dialogar com outros tipos de saberes, como uma obra aberta, problematizadora da realidade. É importante esse material pedagógico estar contextualizado histórica e culturalmente, e não constituir um produto fechado, contendo as ditas "verdades científicas".

Entendemos que livros didáticos, enquanto produções culturais, apresentam modos particulares de produção de significados e valores sociais e culturais, veiculam formas de organização da vida social e, são endereçados a um público leitor principal - alunos/as e docentes das escolas da Educação 
Básica. Nesse sentido, temáticas contemporâneas como a transexualidade que, como já apresentamos, estão em diversos artefatos culturais, como novelas, jornais, programas de TV, livros entre outros, poderiam também estar presentes nos livros didáticos.

A fim de conhecermos se esses saberes são da ciência ou se são aqueles produzidos a partir da ciência presentes nas diferentes mídias sobre os corpos transexuais, apresentados nos livros didáticos de Biologia do Ensino Médio, realizamos um levantamento investigativo, buscando saber se os corpos trans eram mencionados, como eram apresentados, e as enunciações presentes sobre esses. Para tanto, analisamos quinze (15) livros de Biologia para Ensino Médio de 2003 a $2015^{3}$. Na análise nenhum desses livros apresentou algum texto ou infográfico sobre os corpos trans. Eles se detêm a reiterar o binarismo rígido de gênero, os corpos que aparecem são de homens e mulheres, onde a genitalidade está marcada, não havendo nenhuma outra possibilidade de corpos. Assim, corpos-homem e corpos-mulher são apresentados com fins de reprodução.

Nesses livros, existe um espaço privilegiado ao conhecimento anátomofisiológico dos sistemas genitais, à reprodução, ao uso dos métodos anticoncepcionais, aos mecanismos e à prevenção das infecções sexualmente transmissíveis - IST e AIDS. É importante ressaltar que essas temáticas são abordadas como problemas de saúde sexual e reprodutiva, tratadas através dos discursos médico e biológico sobre o funcionamento dos corpos e das doenças para prescrever um autocuidado e, através dele, controlar o corpo e a sexualidade. Esses artefatos vêm funcionando como estratégias para o controle dos comportamentos dos indivíduos - "use camisinha", "não transe", "cuide de seu corpo", "conheça os métodos anticoncepcionais"... Nessa discursividade, temos a aquisição de conhecimentos científicos (categorizações e descrições) dos sistemas genitais - atributo biológico compartilhado por todos/as, independente de sua história e cultura. Assim, os

\footnotetext{
${ }^{3}$ Os livros didáticos de Biologia analisados compõem o acervo da Biblioteca do Centro de Educação Ambiental, Ciências e Matemática da Universidade Federal do Rio Grande - FURG.
} 
discursos científicos engendram os corpos de forma binária, ou seja, como um atributo de natureza biológica, vinculada às características anatômicas, internas e externas, fixando nessas características a sexualidade e as diferenças atribuídas aos homens e mulheres.

Ribeiro et al. destacam que:

A ferramenta teórico-conceitual de Butler permite-nos pensar sobre o papel e tarefas da Biologia e da Medicina na produção das diferenças anatômico-homornal-biológicas quanto aos comportamentos e condutas esperados e produzidos para os indivíduos. Tal tarefa e procedimento, se tomados pelos livros didáticos, possibilitariam que a escola pudesse apresentar outras racionalidades, inclusive para pensar a identidade de gênero, a identidade sexual e os corpos. (2016, p. 82).

Sendo os livros didáticos artefatos culturais que atuam na construção das identidades dos/as alunos/as, uma vez que representam os corpos de meninos e meninas, esses ensinam modos de ser e de estar no mundo. Assim, com relação à forma como os corpos aparecem nos livros didáticos, desvinculados do ambiente, fragmentados, assexuados, sem mãos e nem pés, com um padrão que se repete independente de classe, raça, etnia, credo, os livros privilegiam um discurso hegemônico e "verdadeiro", contribuindo, dessa forma, para a produção de sujeitos universais.

Os livros didáticos, sendo um dos materiais mais utilizados pelos/as professores/as para o planejamento de suas aulas, necessitam ser (re)pensados quanto à sua própria utilização, pois deveriam problematizar as questões e imagens neles apresentadas e permitir que sejam feitas contribuições dos/as alunos/as acerca de outros assuntos que eles não trazem como conteúdo, mas que fazem parte do dia a dia de todos/as nós, num contexto referente à beleza, saúde, doença, obesidade, questões de gênero, sexualidade, entre outras. Dessa forma, a escola proporcionará, efetivamente, discussões sobre essas outras abordagens culturais, e possibilitará que as/os 
alunas/os saibam lidar com as múltiplas representações de corpos existentes, respeitando as diferenças e contribuindo para a desconstrução de binarismos: gordo/magro, alto/baixo, bonito/feio, negro/branco, homem/mulher, homossexual/heterossexual, cisgênero/transgênero,...

Ao problematizar tais questões, no espaço da escola, estaremos provocando fissuras e abrindo brechas para a construção de outras formas de pensar, discutir e abordar os corpos na escola, buscando o entendimento de que existem múltiplos corpos, múltiplos sujeitos, múltiplas formas de ser e de estar no mundo, afinal, os corpos trans estão e necessitam estar dentro da escola e nos livros didáticos.

\section{Produzindo algumas considerações}

Pensarmos a transexualidade, construída na complexa rede que constitui a cultura, possibilita-nos problematizar as formas pelas quais vão sendo produzidos saberes, poderes, conhecimentos, ensinamentos, valores e significados sobre as questões e sujeitos trans no interior de uma cultura e em um determinado tempo histórico.

Atualmente, ainda observamos o quanto a produção de estudos e saberes, ancorados na investigação dos corpos-homens e corpos-mulheres, com o intuito de produzir "verdades" sobre os sujeitos, não apenas apodera-se do corpo, mas, também, da vida, dos desejos, dos prazeres e das escolhas de cada pessoa, instituindo e reforçando alguns binarismos socialmente construídos: homem/mulher, heterossexualidade/homossexualidade, biológico/cultural, normal/anormal, cisgênero/transgêneros, entre outros.

As tecnologias empregadas na produção de saberes científicos acabam por colocar os corpos, os gêneros e as sexualidades presas a uma destinação biológica, ao apontar que os corpos dos sujeitos trans apresentam algo de diferente, ou seja, esse corpo se difere daquilo que se espera, nesses estudos científicos, como desenvolvimento normal da correspondência sexo-gênerodesejo. Nessa direção, tais saberes reforçam uma espécie de "naturalização" 
dos sujeitos, conforme destaca Sousa Filho (2009), quando diz que seu principal efeito é a criação da ideia de que as pessoas cis seriam dadas, inatas, sendo assim normais, ao passo que as pessoas trans teriam uma espécie de transtorno, não sendo a transexualidade nem normal e nem da natureza de homens e mulheres.

Assim, esses saberes produzidos pela ciência constroem discursos e "verdades" que passam a ser tomadas e legitimadas como universais. Para tais estudos, todos os sujeitos, independente de questões culturais e sociais, serão "enquadrados" de acordo com que é estabelecido cientificamente, seja para a heterossexualidade, a homossexualidade, a bissexualidade, como, nesse caso, a transexualidade.

É preciso compreender que ser homem e mulher não está relacionado ao ter um pênis ou uma vagina. Para Butler (2013, p. 24), sendo os gêneros "significados culturais assumidos pelo corpo sexuado, não se pode dizer que ele decorra de um sexo desta ou daquela maneira.”. Assim, colocamos sob suspeita a ideia de que a construção de masculinidades esteja atrelada apenas ao corpo-homem, bem como a produção de feminilidades seja apenas possível no corpo-mulher.

Contudo, a noção de humano e a aquisição do status de humano, socialmente, está articulada à categoria gênero. Os atributos e interpelações, direcionadas aos sujeitos desde quando encontram-se no útero, sustentam o campo discursivo e as relações de poder que legitimam o que pode ser considerado como humano. Para Butler (2007, p. 161), evidenciamos isso "mais claramente nos exemplos daqueles seres abjetos que não aparecem apropriadamente generificados; é sua própria humanidade que se torna questionada". Assim, o sujeito só é reconhecido, ganha vida e adquire inteligibilidade quando segue as normas de gênero, quando segue a ordem compulsória do sexo/gênero/desejo em correspondência ao que se espera para corpos-homens e corpos-mulheres. Isso pode ser evidenciado nos livros didáticos de Biologia analisados neste texto. Eles marcam a inexistência desses outros corpos, que borram e colocam em xeque esse sistema de 
intelegibilidade.

As pessoas trans colocam a norma em evidência, fazem a norma falar, fazem a norma dizer de si e, por isso, produzem desconforto, pois a norma é algo para funcionar no silêncio. Isso está fortemente articulado à noção de coerência e não coerência, sempre uma ficção necessária que inventamos para viver, mas que podemos modificar.

Os corpos trans são produzidos em não obediência da inteligibilidade social, ou seja, em não coerência e continuidade entre sexo/gênero/desejo (BUTLER, 2013). Assim, para os sujeitos que insistem na heterossexualidade como norma e na coerência entre sexo e gênero, os corpos das pessoas trans são tomados como inconformes, abjetos, algo a ser investigado e corrigido. (LONGARAY, 2014).

Preciado (2011), nos aponta que os corpos da multidão queer apresentam-se como centros para a "desterritorialização" da heterossexualidade. Para o autor:

Esse processo de "desterritorialização" do corpo obriga a resistir aos processos do tornar-se "normal". Que existam tecnologias precisas de produção dos corpos "normais" ou de normalização dos gêneros não resulta um determinismo nem uma impossibilidade de ação politíca. Pelo contrário, porque porta em si mesma, como fracasso ou resíduo, a história das tecnologias de normalização dos corpos, a multidão queer tem também a possibilidade de intervir nos dispositivos biotecnológicos de produção de subjetividade sexual. (PRECIADO, 2011, p. 14).

Assim, visibilizarmos as experiências trans com relação aos seus corpos, seus modos de produção e seus trânsitos no espaço escolar nos possibilitam movimentos de rupturas e abertura de brechas para se pensar o sistema heteronormativo no qual somos educados/as.

Através das problematizações tecidas neste texto, procuramos contribuir com algumas das discussões acerca da transexualidade nos espaços 
educativos. Tomar as mídias citadas e os livros didáticos analisados como artefatos culturais, os quais contêm determinadas pedagogias dos corpos, dos gêneros e das sexualidades (re)produtoras de conhecimentos de natureza científica e de (in)visibilidades, possibilitou-nos discutir o quanto seus ensinamentos estão articulados às diferentes maneiras de representar e posicionar os sujeitos com relação aos corpos, gêneros e sexualidades reconhecidas, possíveis e visíveis. Nessa direção, o que propomos é o reconhecimento dessas pedagogias enquanto um dispositivo cultural que, assim como a escola, está engendrado na construção de determinados ensinamentos que nos educam enquanto sujeitos.

\section{Referências}

ARÁN, Márcia; PEIXOTO JÚNIOR, Carlos Augusto. Subversões do desejo: sobre gênero e subjetividade em Judith Butler. Cadernos Pagu, Campinas, n. 28, p. 129147, jan./jun. 2007.

BENTO, Berenice. A Reinvenção do corpo: sexualidade e gênero na experiência transexual. Rio de Janeiro: Garamond, 2006.

As tecnologias que fazem os gêneros. In: Congresso Iberoamericano de Ciência, Tecnologia e Gênero, 8., 2010, Curitiba. Anais... Curitiba: UFPR, 2010. p. 01-13. Disponivel em:

$<$ http://files.dirppg.ct.utfpr.edu.br/ppgte/eventos/cictg/conteudo_cd/E8_As_Tecnolog ias_que_Fazem_os_Gêneros.pdf>. Acesso em: 21 out. 2017.

. Luta globalizada pelo fim do diagnóstico de gênero? In: SANTOS, Luís Henrique Sacchi dos; RIBEIRO, Paula Regina Costa. Corpo, gênero e sexualidade: instâncias e práticas de produção nas políticas da própria vida. Rio Grande: FURG, 2011. p. 89-108.

O que pode uma teoria? Estudos transviados e a despatologização das identidades trans. Revista Florestan, São Carlos, n. 2, p. 46-66, nov. 2014. Disponiível em:

$<$ http://www.revistaflorestan.ufscar.br/index.php/Florestan/article/view/64/pdf_25>. Acesso em: 20 nov. 2017.

BUTLER, Judith. Corpos que pesam: sobre os limites discursivos do "sexo". In: LOURO, Guacira Lopes. O corpo educado: pedagogias da sexualidade. Belo Horizonte: Autêntica, 2007. p. 151-172. 
Problemas de gênero: feminismo e subversão da identidade. Rio de Janeiro: Civilização Brasileira, 2013.

D'ALAMA, Luna. Transexual pode se descobrir já na primeira infância, dizem especialistas. Disponível em: <http://g1.globo.com/ciencia-esaude/noticia/2013/03/transexual-pode-se-descobrir-ja-na-primeira-infancia-dizemespecialistas.html>. Acesso em: 11 dez. 2017.

FISCHER, Rosa Maria Bueno. O estatuto pedagógico da mídia: questões de análise. Educação e Realidade, Porto Alegre, v. 22, n. 2, p. 59-80, dez. 1997.

FOUCAULT, Michel. A ordem do discurso. Aula inaugural no Collège de France, pronunciada em 2 de dezembro de 1970. São Paulo: Loyola, 2006. 79 p.

História da sexualidade I: a vontade de saber. 18. ed. Rio de Janeiro: Graal, 2007a. 176 p.

Microfísica do poder. Rio de Janeiro: Graal, 2007b. 295 p.

GLOBO Repórter. Transgênero: origem pode ser biológica e começar na gestação. Edição 23 set. 2016. Disponível em: <http://g1.globo.com/globoreporter/noticia/2016/09/transgenero-origem-pode-ser-biologica-e-comecar-nagestacao.html>. Acesso em: 20 nov. 2017.

LONGARAY, Deise Azevedo. A (Re)Invenção de si: investigando a constituição de sujeitos gays, travestis e transexuais. 226 f. Tese de Doutorado. Programa de PósGraduação em Educação em Ciências: Quimíca da Vida e Saúde da Universidade Federal do Rio Grande, 2014.

LOURO, Guacira Lopes. Um corpo estranho: ensaios sobre sexualidade e teoria queer. Belo Horizonte: Autêntica, 2004.

LOURO, Guacira Lopes. Gênero, sexualidade e educação: uma perspectiva pósestruturalista. Petrópolis: Vozes, 2001.

LUCON, Neto. 'Não acreditem nos livros de biologia', diz Sofia Favero, criadora da 'Travesti Reflexiva'. Entrevista 24 ago. 2014. Disponível em: $<$ http://www.nlucon.com/2014/08/travesti-reflexiva-sofia-favero-transfobia.html>. Acesso em: 10 set. 2017.

MELO, José Marques de; TOSTA, Sandra Pereira. Midia \& Educação. Belo Horizonte: Autêntica, 2008. 111 p.

NOVAES, Adauto. A ciência no corpo. In: (Org.). O homem-máquina: a ciência manipula o corpo. São Paulo: Companhia das Letras, 2003. p. 07-14.

ORTEGA, Francisco. O corpo incerto: corporiedade, tecnologias médicas e cultura contemporânea. Rio de Janeiro: Garamond, 2008. 
PRECIADO, Paul (Beatriz). Multidões queer: notas para uma política dos "anormais". Revista Estudos Feministas, Florianópolis, v. 19, n. 1, jan./abr. 2011, p. $11-20$.

RIBEIRO, Paula Regina Costa et al. O ensino de biologia e suas articulações com as questões de corpos, gêneros e sexualidades. Revista Bio-Grafía, Bogotá, v. 8, n.16, p. 77-86, jan./jun. 2016. Disponível em: <http://repositorium.sdum.uminho.pt/bitstream/1822/52190/1/2016-

Ribeiro...Vilaca.pdf $>$. Acesso em: 20 set. 2017.

SOUZA, Nádia Geisa S. de. "Fases da vida": discursos biológicos, religiosos, midiáticos. In: WORTMANN, Maria Lúcia Castagna et al. Ensaios em estudos culturais, educação e ciência. Porto Alegre: Editora da UFRGS, 2007. p. 19-34.

SOUSA FILHO, Alípio de. Teorias sobre a gênese da homossexualidade: ideologia, preconceito e fraude. In: JUNQUEIRA, Rogério. D. Diversidade Sexual na Educação: problematizações sobre a homofobia nas escolas. Brasília: Ministério da Educação, Secretaria de Educação Continuada, Alfabetização e Diversidade, UNESCO, 2009. p. 95-124.

VEIGA-NETO, Alfredo. Foucault e a educação. Belo Horizonte: Autêntica, 2007.

Livros didáticos analisados:

FAVERETTO , José Arnaldo e MERCADANTE, Clarinda. Biologia - volume único. $1^{\mathrm{a}}$ ed. São Paulo: Moderna, 2005.

LOPES, Sônia e ROSSO, Sergio. Biologia - volume único. $1^{\mathrm{a}}$ ed. São Paulo: Saraiva, 2005. $10^{\mathrm{a}}$ tiragem, 2010.

LINHARES, Sérgio e GEWANDSZNAJDER, Fernando. Biologia hoje. $2^{\mathrm{a}}$ ed. São Paulo: Ática, 2013. Volume 3: Genética evolução ecologia.

AMABIS, José Mariano e MARTHO, Gilberto Rodrigues. Biologia em contexto. $1^{\text {a }}$ ed. São Paulo: Moderna, 2013. Volume 2: Adaptação e continuidade da vida.

SILVA JÚNIOR, César da; SASSON, Sezar; JÚNIOR, Nelson Caldini. $11^{a}$ ed. São Paulo: Saraiva, 2013. Volume 1: Biologia (Ensino médio). LINHARES, Sérgio e GEWANDSZNAJDER, Fernando. Biologia hoje. $2^{\text {a }}$ ed. São Paulo: Ática, 2013. Volume 2: Os seres vivos.

SÍDIO, Machado. Biologia: ciência \& tecnologia. $1^{\text {a }}$ ed. São Paulo: Scipione, 2009.

LINHARES, Sérgio e GEWANDSZNAJDER, Fernando. Biologia hoje. $2^{\mathrm{a}}$ ed. São Paulo: Ática, 2013. Volume 1: citologia/ reprodução e desenvolvimento/ histologia/ origem da vida.

BRÖCKELMANN, Rita Helena. Conexões com a Biologia. $1^{\mathrm{a}}$ ed. São Paulo: Moderna, 2013. Volume: 1. 
FAVERETTO, José Arnaldo. 360 : biologia: diálogos com a vida: partes 1, 2 e 3 volume único. $1^{\mathrm{a}}$ ed. São Paulo: FTD, 2015. Parte 1.

. $360^{\circ}$ : biologia: diálogos com a vida: partes 1,2 e 3 - volume único. $1^{\mathrm{a}}$ ed. São Paulo: FTD, 2015. Parte 2.

. $360^{\circ}$ : biologia: diálogos com a vida: partes 1,2 e 3 - volume único. $1^{\mathrm{a}}$ ed. São Paulo: FTD, 2015. Parte 3.

. $360^{\circ}$ : biologia: caderno de revisão. $1^{\mathrm{a}}$ ed. São Paulo: FTD, 2015.

FAVERETTO, José Arnaldo. 360 : biologia: caderno de atividades/ENEM e vestibular . $1^{\mathrm{a}}$ ed. São Paulo: FTD, 2015.

. $360^{\circ}$ : biologia: caderno de infográficos . $1^{\mathrm{a}}$ ed. São Paulo: FTD, 2015.

Recebido em março de 2018.

Aprovado em dezembro de 2018. 